\title{
Current Topics in High Voltage Engineering
}

\author{
Tadasu Takuma, Member (Central Research Institute of Electric Power Industry)
}

\begin{abstract}
The paper first reviews the recent trends of research subjects in high voltage engineering, and explains several current topics now actively studied. They are concerning electric field calculation, laser induced lightning, high voltage testing, gas insulation, and so on. The paper also describes the author's view on the future in high voltage engineering.
\end{abstract}

\section{Introduction}

What is high voltage (HV) engineering?

What research items should I take up as current topics in $\mathrm{HV}$ engineering?

In order to review the $\mathrm{HV}$ engineering, I must start with these questions. High voltage engineering is related to very wide fields of sciences and technologies, which range from mathematics, basic physical processes of electrons, atoms and molecules to various kinds of $\mathrm{HV}$ equipment now utilized in power systems. According to this interdisciplinary or multi-field feature, the definition of "HV engineering" changes with the scope of a scientific or technological society, magazine, meeting, and so on, where the word is used. Sometimes HV engineering covers a wide range, for example, when it includes electrical discharge in various media and/or electric power equipment. At other times it is fairly limited or narrow-ranging.

The sub"session "High Voltage Engineering \& Power Apparatus (GIS, GCB)" at the International Session in IEE Japan \& Energy '93 is a still wideranging one. My selection will be inevitably arbi- trary. Here I first review the recent trends of research subjects in $\mathrm{HV}$ engineering mainly from the International Symposium on High Voltage Engineering. After the general view I take up several topics now actively studied or in development.

\section{Technical Subjects of the ISH}

The ISH, International Symposium on HV Engineering, is the largest and only one international meeting in the field of $\mathrm{HV}$ engineering. It was proposed by the late Prof. Prinz of the Technical University Munich, Germany (West Germany at that time), and started there in 1972 with 93 papers from 18 countries. The 8 th ISH was held at Yoko. hama, Japan, in August this year.

Table 1 shows some data concerning the seven previous Symposiums. It can be seen that the number of presented papers has remarkably increased with every Symposium. The 7th ISH registered the highest number both in papers (466) and participants (594).

Table 2 shows the ratio of papers in technical subjects, which roughly correspond to the grouping at the 7th (Dresden) and the 8th (Yokohama). However, as the technical subjects considerably

Table 1 Number of Papers in the ISH's

\begin{tabular}{cllc}
\hline Year & Site & $\begin{array}{c}\text { Number of papers } \\
\text { (countries) }\end{array}$ \\
\hline 1. & 1972 & Munich & $93(18)$ \\
2. & 1975 & Zurich & $152(27)$ \\
3. 1979 & Milan & $277(30)$ \\
4. 1983 & Athens & $264(31)$ \\
5. 1987 & Braunschweig & $384(33)$ \\
6. 1989 & New Orleans & $444(34)$ \\
7. 1991 & Dresden & $466(37)$ \\
\hline
\end{tabular}


Table 2 Ratio (Percentage) of Papers Divided into Subjects of the Recent ISH's

\begin{tabular}{lrrrr}
\hline \multicolumn{1}{c}{ Subject } & 5 th & 6 th & 7 th & 8 th \\
\hline 1. Electric Field-Calculation and Measurement & 14 & 14 & 8 & 5 \\
2. Solid and Liquid Dielectrics and Insulation & 13 & 16 & 18 & 11 \\
3. Gaseous Dielectrics and Insulation, Vacuum & 12 & 15 & 9 & 10 \\
4. Air Breakdown, Outdoor Insulation, Pollution & 19 & 19 & 18 & 19 \\
5. HV Measurement and HV Testing & 21 & 7 & 18 & 11 \\
6. PD Measurement and Diagnostics & 6 & 8 & 11 & 14 \\
7. Lightning, Fast Transients, EMC & 11 & 13 & 12 & 18 \\
8. Special Problems: Electrostatics, Precipitators, Biological HV Effects, & 4 & 8 & 6 & 12 \\
Pulsed Power, etc. & & & \\
\hline
\end{tabular}

differ with every Symposium, I modified them as in Table 2 and correspondingly redistributed papers. The percentage at the 8 th ISH is for submitted abstracts, and not for papers to be presented.

The following features can be pointed out from Table 2.

(a) Increasing contributions; Subjects 6 and 8. This reflects the increasing importance of diagnostic techniques toward higher reliability of HV equipment, and the development of new or miscellaneous HV applications other than power facilities.

(b) Nearly constant contributions; Subjects 2, 4 and 7. It should be noted that Subject 4 with constantly about $20 \%$ owes its considerably large part of contributions to those from developing countries.

(c) Decreasing contributions; Subject 1. This point is later discussed. Subject 3 "Gaseous dielectrics and insulation" also shows a somewhat decreasing tendency.

(d) Fluctuating contributions; Subject 5.

\section{Numerical Field Calculation $\cdots$ CAD (CAE)}

Calculation of electric fields with the aid of a computer is now an inevitable tool for analyzing discharge phenomena and designing various kinds of $\mathrm{HV}$ equipment. Among several numerical methods, the Charge Simulation Method (CSM) founded by Dr. Steinbigler in the Technical University Munich is now widely utilized as the most accurate and perhaps user-friendly.

The decrease of papers belonging to the subject of electric field calculation, as shown in Table 2 , means that the numerical methods have already been established as reliable and useful tools in simple electrostatic conditions, thus leaving few innovative ideas to be studied. The highlight in this subject several years ago was the development of an optimization technique, that is, an automatic design method of an optimal profile of a conductor or an insulating solid support. One example is concerning a constant-field condition on the surface of a conductor. However,even this topic makes few papers now.

In other words, there remain problems which are so difficult to propose new technique, or lack generalization to make a paper. I will point out such important but difficult topics;

a. fields with space charge,

b. fields composed of multiple media, in particular, non-linear problems with field-dependent characteristics,

c. time-dependent fields, especially, for very fast voltages,

d. complex problems, when electrical characteristics depend on other physical values, such as mechanical and/or thermal characteristics.

The other important direction is the development of a CAD (Computer Aided Design) or CAE (CA Engineering) System of numerical field caluculation, which enables a more generalized calculation tool on one hand and a user-friendly system on the other hand. It should be noted that these two requirements often contradict each other. Two exemplary projects of CAD Systems are briefly described as follows.

\section{a. VENUS}

This system is now in development as the cooperative work of universities and companies in Germany. It aims at establishing the most generalized system in all aspects of field calculation such as conditions, arrangements, and methods. A knowledge-based consulting system named NUMEX is also being developed to permit every userfull-auto- 
matic preparation of input data.

\section{b. CADEF}

This system belongs to Prof. Okubo's group in Nagoya University. It typically applies to a 32-bit personal computer for calculating axi-symmetrical fields by the CSM. They are also trying to apply an expert system for selecting a suitable arrangement of contour points and fictitious charges.

\section{Laser Induced Lightning or Discharge}

Lightning has been studied for such a long time since the pioneering experiment of Franklin in 1752. Studies on lightning are greatly diversified from observation, generating overvoltages, and protecting techniques as a lightning rod.

One of new research topics on lightning is regarding laser induced lightning (LIL). This is the technique which aims at inducing a lightning stroke to a harmless place artificially along a laser-produced plasma channel, thus protecting important facilities. Forming a long plasma channel of more than $100 \mathrm{~m}$ seems necessary for LIL, because the height of a bottom of thunderclouds is usually at least several hundred meters. As a plasma channel of 50 to $60 \mathrm{~m}$ in length has already been produced, it seems technically possible to make it longer than $100 \mathrm{~m}$. However, a long laser-produced plasma channel is not always dense and effective enough to induce sparkover.

About ten organizations are now carrying out experiments in Japan, with various kinds of laser beams. All of them are for the discharge with $\mathrm{HV}$ sources, not for natural lightning. The largest distance of induced sparkover is $8.5 \mathrm{~m}$ by the group of Osaka University and Kansai Electric Power Company using a $\mathrm{CO}_{2}$ laser with the energy of $100 \mathrm{~J}$ and multi-focus concave mirror. It seems very important for the realization of LIL to make clear mechanisms of plasma formation and sparkover induction.

Two remarkable features can be pointed out for sparkover induction. First, the sparkover voltage shows minimum in relation to the delay time of impulse voltage application after plasma production. The time for the minimum value is typically 50 to 100 microsecs. Secondly, the polarity effect is reversed in non-uniform fields owing to the presence of laster-produced plasma. Without plasma forma- tion, the impulse sparkover voltage for a rod-toplane gap is twice as high for the rod-negative condition as for the rod-positive one. With laserinduced plasma, the rod-negative condition gives lower sparkover voltage.

\section{High Voltage Tests $\cdots$ Standards}

Procedures as well as applied voltage values in HV tests are a very important, almost decisive, factor which determines dimensions and thus cost of $\mathrm{HV}$ equipment. Two topics are to be noted in this subject. One is the rationalization of HV test procedures in standards, and the other is an accreditation system for HV tests.

The Japanese Electrotechnical Committee (JEC), which corresponds to the international organization IEC, is now improving or amending its publication "Testing Voltage Standards". Such improvement is due to recent developments and researches performed both internationally and in Japan as in the following.

(a) Development of high-performance $\mathrm{ZnO}$ arresters, which has brought a remarkable reduction of various overvoltages.

(b) Development of innovative insulation techniques, such as gas insulation for switchgears.

(c) Development of more accurate and reliable analyzing methods with computers, such as for electric fields and transient overvoltages. This has enabled obtaining efficient insulating performances and accurate overvoltages appearing in power systems. Two typical examples are the CSM and the EMTP (Electromagnetic Transients Program).

(d) Investigations for UHV (Ultra High Voltage) systems of $1000 \mathrm{kV}$ class in ac.

The featuring points of the amendment are summarized as follows.

(1) Ac test; The short-term ac test, or oneminute test, which the JEC Standard provides, for example $750 \mathrm{kV}$ application for $500 \mathrm{kV}$ equipment, will be abolished at higher voltages. It will be replaced by a long-substained test with PD (partial discharge) measurement. The PD test is considered more effective in detecting possible defects and less harmful to insulating materials.

(2) Lightning impulse test; Magnitude of 
applied impulses will be considerably diminished.

(3) Switching impulse test; No test with switching impulses will be neeed.

I would like to suggest two points concerning the rationalization of $\mathrm{HV}$ tests. First, further research is necessary, in particular, on the life endurance test of solid insulating supports. That is to say, the deterioration mechanism of supports from partial discharge to final breakdown is not yet fully understood. Secondly, keeping pace with the amendment of the standards or the lowering of testing voltage, it is also possible to apply already installed facilities to higher voltage than planned. Some electric power companies in the USA have tried and are further planning to raise the insulation level, for example, from 115 to $230 \mathrm{kV}$, and from 69 to 115 or $138 \mathrm{kV}$ at several substations.

\section{GIS -.Insulation Diagnostics}

Gas insulation using compressed $\mathrm{SF}_{6}$ gas is considered a sufficiently established insulation system of switchgears with higher reliability (less frequent failures) than air insulated ones. In Japan, it is the prime choice for newly built substations. The very high electric field in a gap, however, brings vulnerability of insulation, sensitive to local field enhancement, such as caused by foreign conducting particles. There are already a great number of papers concerning the effect of particles, mechanisms of breakdown induction, protecting techniques, and so on. These studies are still going on. Below, I only briefly explain two recent topics in $\mathrm{SF}_{6}$ gas insulation ; (a) development of diagnostic techniques, and (b) new applications.

The utmost reliability is of high importance in GIS, because much longer downtime is required after a major fault than in conventional substations, and furthermore, direct visual check of live parts is impossible during operation. Important for that is not only improvement of design, manufacturing and assembly, but also development of effective diagnostic techniques for detecting abnormal conditions in-side GIS components at an appropriate period before a final breakdown or fault. Various techniques have been developed so far, and some of them are already in practice. Their working princi- ples are roughly divided into mechanical (acoustic detection), chemical (gas checking), electrical (PD measurement), and so on.

In my opinion, diagnostic techniques for GIS are not yet at a satisfactory level, partly because it contains many kinds of possible abnormal conditions or defects and secondly, a local defect very rapidly leads to breakdown in its final stage. The recent efforts are stressed on employing AI technology, or an expert system, to improve the reliability and sensitivity. Furthermore, some Japanese util. ities are trying to apply an integrated diagnostic system which monitors a numer of checking items in GIS.

\section{New Applications of Gas Insulaton DC Gas Insulation}

As already described, $\mathrm{SF}_{6}$ gas insulation technique has been successfully developed in ac power systems. The recent progress of dc power transmission projects is promoting the development of highly reliable dc equipment with space-saving potential. One possibility for that is the application of compressed $\mathrm{SF}_{6}$ gas insulation technique in dc switchgears.

One of the difficulties with dc gas isulated equipment (so-called dc-GIS) is the charge accumulation on solid insulating supports (spacers) under $\mathrm{dc}$ stress. The static surface charge caued by prolonged dc stress has the possibility of decreasing more or less the insulating ability of spacers. There are also some cases where such dc stress conditions occur in ac GIS's. One is the case of a GIS connected to cables. A part of the GIS is exposed to dc stress due to the dc withstand voltage test of the cables, an onsite test method customarily employed in Japan. Another case is the dc strees on open-side buses due to the residual charge left when disconnectors interrupt charging current.

\section{Gas-Insulated Transformers}

Insulating oil may bring about fire, explosion, and contamination problems if it leaks. It may be highly troublesome for substation equipment in densely populated areas. From this point of view, Japanese power utilities have done research and development 
of gas-insulated transformers ( $\mathrm{GITr}$ ) for more than ten years. Various cooling structures have been developed, and some of them are already working at a few voltage classes. Three principal types are as follows. Coolant is perfluorocarbon $\left(\mathrm{C}_{8} \mathrm{~F}_{16} \mathrm{O}\right)$ liquid in all three types.

Type A: The core and winding of the transformer are immersed in the coolant. The coolant plays a role similar to oil in a conventional oil-filled transformer.

Type B (gas-vapor cooling type): The coolant is circulated through the core and winding. Vaporization of sprayed liquid cools these parts.

Type C (separate type): The coolant flows through cooling panels wounded along with the sheet winding.

Further research and development works are needed for GITr in the following aspects.

a. Establishing long-term reliability

b. Development of diagnostic techniques

c. Redution in size, weight, and cost.

\section{Future}

So far, the development of $\mathrm{HV}$ engineering has been closely related to $\mathrm{HV}$ power transmission. In other words, raising ac or dc voltage in commercial power systems has been a great incentive to HV engineering. The present time is, in this sense, the "electric power period", as Prof. Kind named in his ceremonial speech at the 5th ISH in Braunschweig. Together with the increase of transmission voltage, however, we should not forget a number of innovative technologies performed in material, equipment, and analytical fields.

Tabel 3 lists such motive forces as I consider have greatly contributed or will further contribute to the development of HV engineering. Some important points are commented.

(a) New materials cause a drastic change or
Table 3 Factors Possibly Contributing to the Development of HV Engineering

1. Rise of Transmission Voltage - UHV, SHV (Super HV)

2. Transmission and distribution - enclosed long-distance transmission line

3. Power equipment-electronics-applied equipment, super-conducting equipment

4. Environment-EMI, EMC, environment-oriented facilities

5. HV or electrical discharge applications

6. New materials

7. Nuclear fusion

great development, as exemplified by $\mathrm{SF}_{6}$ gas, $\mathrm{ZnO}$, and epoxy resin.

(b) Most of the fundamental changes have been initiated in the past from industry, although universities have contributed to further development. Exception lies in the field of analytical techniques.

High voltage and high current are the necessary condition for obtaining or transmitting high energy. Even if the voltage of commercial ac and dc power systems attains saturation, $\mathrm{HV}$ will be required in various new fields using electrical discharge, electrostatics, pulsed power, and so on. Such a trend can be seen in the increase of papers belonging to Subject 8 at the recent ISH's as in Table 2.

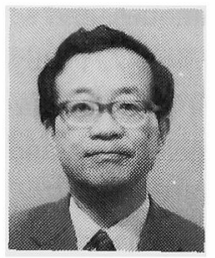

Tadasu Takuma (Member)

$\mathrm{He}$ is an Associate Vice President in CRIEPI (Central Research Institute of Electric Power Industry). He holds the $\mathrm{MS}$ and $\mathrm{PhD}$ degrees from Tokyo University. He received the Maxwell Premium in 1975 from the Institution of Electrical Engineers, Great Britain, and the 1981 as well as 1991 Book Prize from the IEE, Japan. He is a Fellow member of the IEEE. 